\title{
Coupling between Photosystem II electron transport and carbon fixation in microphytobenthos
}

\author{
E. P. Morris ${ }^{1,2}$, R. M. Forster ${ }^{1,3}$, J. Peene ${ }^{1}$, J. C. Kromkamp ${ }^{1, *}$ \\ ${ }^{1}$ Netherlands Institute of Ecology (NIOO-KNAW), Centre for Estuarine and Marine Ecology, Korringaweg 7, 4401 NT, \\ Yerseke, The Netherlands \\ ${ }^{2}$ Present address: Departamento de Biología (Área de Ecología), Facultad de Ciencias del Mar y Ambientales, \\ Universidad de Cádiz, Puerto Real S/N, 11510 Cádiz, Spain \\ ${ }^{3}$ Present address: Centre for Environment, Fisheries and Aquaculture Science, Lowesoft Laboratory, Pakefield Road, \\ Lowestoft, Suffolk NR3 3OH, UK
}

\begin{abstract}
Photosynthetic parameters of a microphytobenthic (MPB) biofilm grown in a tidal mesocosm were measured on undisturbed sediment using variable fluorescence-based measurements of electron transport rate (ETR), as well as by ETR and ${ }^{14} \mathrm{C}$ assimilation measurements in optically thin suspensions of algal cells. Absorption cross-sections of the MPB suspensions were quantified using the quantitative filter technique and by reconstruction using HPLC-derived pigment concentrations. Photosynthetic parameters derived by the 3 methods were compared on 3 days, representing different biofilm growth/[chl a] conditions, at the start, middle and end of the daytime tidal emersion. Comparisons of ETR and radioisotope-derived photosynthetic parameters measured on optically thin suspensions were not significantly different, confirming that with an appropriate estimation of the irradiance absorbed by Photosystem II (PSII), under optically well-defined conditions, variable fluorescence is a reliable measure of MPB photosynthetic rates. In contrast, significant differences of up to $60 \%$ were observed between the maximum photosynthetic capacity $\left(P_{\max }^{\mathrm{B}}\right)$ measured on undisturbed sediment and in suspensions. These differences were observed at high [chl a] (coinciding with low growth rates) towards the end of emersion periods. Comparison of the effective quantum efficiency $\left(\Delta F / F_{\mathrm{m}}\right)$ at the highest light steps of photosynthetic-irradiance $(P-E)$ curves suggested that the overestimation was due to the poor definition of the complex sediment optics, which interacted presumably with photo-taxis and/or single species migrations. Definition of the optics within undisturbed sediments, particularly considering the complex effects of migration, is a serious challenge, limiting the application of variable fluorescence techniques in situ on undisturbed sediments.
\end{abstract}

KEY WORDS: Variable fluorescence $\cdot{ }^{14} \mathrm{C}$ uptake $\cdot$ Microphytobenthos $\cdot$ Maximum photosynthetic capacity $\cdot$ Maximum quantum yield of photosynthesis $\cdot$ Sediment $\cdot$ Absorption cross-section $\cdot$ PAM fluorescence

\section{INTRODUCTION}

Benthic microalgae or microphytobenthos (MPB) form highly productive natural ecosystems in intertidal areas (Cahoon 1999). They are an important food source for both benthic and pelagic communities (MacIntyre et al. 1996, Underwood \& Kromkamp 1999) and have also been linked to sediment stabilisation (Underwood \& Paterson 2003). Quantification of primary carbon production $\left(\mathrm{P}^{\mathrm{c}}\right)$ of $\mathrm{MPB}$ is important for understanding intertidal community dynamics and estuarine food-webs (Middelburg et al. 2000).

Various methods for quantifying the primary production of intertidal sediments have been developed, each 
with their own specific advantages and disadvantages (reviewed by Underwood \& Kromkamp 1999). In situ tracer incubations measure the fixation of ${ }^{13} \mathrm{C}$ or ${ }^{14} \mathrm{C}$ from bicarbonate solution applied to the sediment surface (Middelburg et al. 2000); however, calculations of fixation rates can be difficult due to the unknown specific activity of the tracer in the sediment pore water (Vadeboncoeur \& Lodge 1998). This problem may be serious in cohesive sediments (Jonsson 1991), or in dense biofilms where drawdown of the porewater DIC pool is extremely fast and atmospheric $\mathrm{CO}_{2}$ is the main inorganic carbon source. In contrast, photosynthetic measurements using suspensions of MPB cells in a medium (typically filtered seawater) can give useful information about photosynthetic characteristics under controlled temperature and irradiance conditions (Blanchard \& Cariou-Le Gall 1994, MacIntyre \& Cullen 1995). However, the photosynthetic rates obtained using suspensions may not represent in situ rates, because the physico-chemical gradients existing in the sediments are disturbed.

Variable chlorophyll fluorescence analysis is a relatively new technique that can potentially be used to non-destructively quantify photosynthetic rates of MPB in situ. According to theory, using either 'multiple' or 'single' turnover saturation kinetics (see Kromkamp \& Forster 2003) the effective quantum efficiency of Photosystem II (PSII) $\left(\Delta F / F_{\mathrm{m}}{ }^{\prime}\right)$, which generally represents the effective quantum efficiency of photosynthesis $\left(\Phi_{\mathrm{P}}\right)$ (Genty et al. 1989), can be derived at a range of irradiances. If $\Delta F / F_{\mathrm{m}}$ ' is then multiplied by the irradiance absorbed by PSII, the rate of non-cyclic electron transport (ETR) can be calculated (Hofstraat et al. 1994, Kromkamp \& Forster 2003), which can be converted to a photosynthetic rate by multiplying by the electron use efficiency $\left(\Phi_{\mathrm{e}}\right.$, mol C fixed per mol electrons produced by PSII) (Gilbert et al. 2000).

ETR of algal suspensions is often linearly correlated to $\mathrm{O}_{2}$-production or $\mathrm{C}$-fixation at limiting irradiances; however, sometimes at saturating irradiance, ETR can under- or overestimate the maximum rate of photosynthesis (Flameling \& Kromkamp 1998, Hartig et al. 1998, Masojídek et al. 2001). Comparisons of ETR and standard measures for the quantification of undisturbed MPB biofilm photosynthetic rates are rare, and the published results are often contradictory (Barranguet \& Kromkamp 2000, Perkins et al. 2002, Serôdio 2003). In general, pin-pointing the exact cause of deviations between ETR and standard measures reported in the literature is difficult because of the variety of 'standard' methods and the different levels of approximation for the amount of light absorbed by PSII.

Furthermore, in comparison to measurements in suspension, a number of additional complications are introduced when trying to assess ETR of undisturbed
MPB biofilms. Measuring the chlorophyll a (chl a)specific optical cross-section of cells poses methodological problems due to the highly scattering nature of sediments. The severe attenuation of irradiance within sediments (Kuhl \& Jorgensen 1992) combined with the vertically structured distribution of chl a within the photic zone makes estimations of the mean irradiance reaching the algal cells very difficult. This vertical structure also means that the fluorescence signal from deep chl a layers contributes to fluorescence measurements made at the sediment surface (Forster \& Kromkamp 2004, Serôdio 2004). As a result, the measured $\Delta F / F_{\mathrm{m}}$ ' at the sediment surface can overestimate the 'true' $\Delta F / F_{\mathrm{m}}$ ', especially in high light, and for this reason it might be better to estimate the inherent photosynthesis parameters under optically welldefined conditions (e.g. in thin slurries). Nevertheless, theoretical proxies have been developed (Serôdio 2003, Forster \& Kromkamp 2004) and tested (Serôdio et al. 2007) to account for the effect of upwelling fluorescence from subsurface algae, allowing estimates of depth-integrated primary production of MPB from surface measurements. In addition, not correcting for 'background fluorescence' has also been shown to severely influence measurements of variable chlorophyll fluorescence in the water column (Cullen \& Davis 2003), and the resultant artefacts also apply to sediments. Finally, to compound all of these difficulties, motile MPB cells can vertically migrate, as single cells of the same population or as a whole community over tidal cycles (Kromkamp et al. 1998, Underwood et al. 2005), and in response to changing irradiance conditions (photo-taxis) (Jesus et al. 2006a), seriously complicating the measurement of ETR (Oxborough et al. 2000, Perkins et al. 2001, 2002).

Thus, our aim was to assess the effectiveness of using variable fluorescence techniques to measure the photosynthetic parameters of a MPB biofilm grown in a tidal tank system, providing controlled conditions, and a range of [chl a]/growth rates over which to compare methods. Photosynthetic rates were estimated using ETR and ${ }^{14} \mathrm{C}$ assimilation measurements carried out on optically thin suspensions of MPB in filtered seawater (removing any effects related to the vertical structure of the sediment). ETR was also used to estimate photosynthetic rates in situ on the undisturbed biofilm. Estimates of the light absorbed by the assemblage were calculated using measured specific absorption cross-sections. Fluorescence-based measurements were converted to rates of carbon fixation using previously published coefficients. Photosynthetic rates derived by each method (ETR in situ, ${ }^{14} \mathrm{C}$ suspension, and ETR suspension) at the start, midway, and end of daytime tidal emersions were compared at 3 different growth stages of the biofilm. 


\section{MATERIALS AND METHODS}

Tidal tank mesocosms. Sediment was collected in February 2002 from an intertidal flat on the northern shores of the turbid, eutrophic Westerschelde estuary, SW Netherlands (Biezelingsche Ham, 51 26' N, $\left.3^{\circ} 55^{\prime} \mathrm{E}\right)$. The sediment consisted of poorly sorted, fine sands (mean grain size $0.14 \mathrm{~mm}$ ) with an organic matter content of $7.4 \pm 2.7 \%$ (K. Wolfstein pers. comm.). The sediment was sieved ( $1 \mathrm{~mm}$ mesh size), to remove macrobenthos, and autoclaved, to kill the remaining meiobenthos and microbiota. This sediment was used to fill 4 identical rectangular plastic trays $(30 \times 50 \mathrm{~cm}$ wide, $12 \mathrm{~cm}$ high) that were placed in the tidal mesocosm. A computer controlled system was used to regulate the inflow and outflow of water to the $1000 \mathrm{l}$ seawater reservoir. Valves regulated the tidal inflow/ outflow so that there was very little hydrodynamic disturbance to the sediment surface, thus preventing resuspension. The emersion time of the sediment surface was $20 \mathrm{~h} \mathrm{~d}^{-1}$ (split into two $10 \mathrm{~h}$ low tides from 09:00 to 19:00 and 21:00 to 07:00 h). The emersion times were comparable with the high shore collection site at Biezelingsche Ham, and were set at the same time of day throughout the experiment (i.e. no tidal cycle lag). The photo-period and irradiance were constant throughout the experiment at $12 \mathrm{~h}$ and $200 \mu \mathrm{mol}$ quanta $\mathrm{m}^{-2} \mathrm{~s}^{-1}$, starting at 08:00 $\mathrm{h}$ and ending at 20:00 h, to give a daily photon dose of $8.6 \mathrm{~mol}$ quanta $\mathrm{m}^{-2}$. The whole system was constructed in a temperature-controlled room set to $15^{\circ} \mathrm{C}$. Salinity of the overlying seawater was 29. Initial nutrient concentrations of the seawater were $54.9 \mu \mathrm{mol} \mathrm{NO} \mathrm{I}^{-1}, 6.9 \mu \mathrm{mol} \mathrm{NH}$

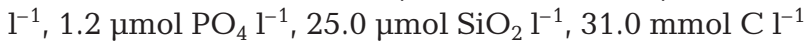
(TIC) and $119.6 \mu \mathrm{mol} \mathrm{C} \mathrm{l}^{-1}$ (DOC).

MPB-enriched sediment was collected by scraping the surface layer from the same intertidal site; from this, a suspension of epipelic MPB was collected using the lens tissue method (Eaton \& Moss 1966). The dilute suspension of MPB cells, which qualitatively appeared to be dominated by an epipelic Navicula sp., was then sprayed over the trays using a simple household plant mister. The trays were inoculated on 8 February 2002, and growth of the MPB biofilm was monitored for $19 \mathrm{~d}$.

Sediment chlorophyll concentrations and growth rates. Chlorophyll concentrations of the sediment surface were recorded at high temporal resolution (every $30 \mathrm{~min}$ ) over $19 \mathrm{~d}$ using field spectrometry (Forster \& Jesus 2006, Kromkamp et al. 2006). Using the reflectance spectra, the normalised difference vegetation index (NDVI) was calculated and converted to surface chl a equivalent units $\left(\mathrm{mg} \mathrm{m}^{-2}\right)$ using the regression of Kromkamp et al. (2006). Mean daily [chl a] was fitted to a logistic growth model using least squares criterion (Blanchard et al. 2001). A 5 d lag period before logistic growth began was observed at the beginning of the experiment. No vertical migration of the assemblage was observed during the emersion periods.

Pigment determinations. Sub-samples of the MPB suspensions used in photosynthesis-irradiance $(P-E)$ experiments (see next subsection) were collected on Whatman GF/F filters for pigment extraction in dimethylformamide (DMF). Reversed-phase HPLC analysis was performed with a C-18 column, and Waters 2690 separation module running a ternary gradient system consisting of $85 \%$ methanol:water, $90 \%$ acetonitrile:water, and ethyl acetate (Kraay et al. 1992). Pigments were detected using a Waters 996 photodiode array and a Waters 474 fluorescence detector and classified with Millennium software, according to a spectral library of known pigments. Quantifiable chlorophyll pigments included chls $a, b$, and $c_{1} / c_{2}$, chlorophyllide $a$, pheophorbide $a$ and pheophytin $a$.

Photosynthesis of the microphytobenthic assemblage. On Days 7,12 and 15 after inoculation, measurements of the $P-E$ relationship were carried out at the start (10:00 h, $1 \mathrm{~h}$ emersion), middle (13:00 h, $4 \mathrm{~h}$ emersion), and end (16:00 h, $7 \mathrm{~h}$ emersion) of the daytime low tide.

Photosynthetic ETR were measured both in situ on undisturbed sediment and on suspensions of MPB cells. The rate of carbon fixation was also measured on suspensions of MPB cells using a radiocarbon assay (see 'Radiocarbon assay' below). Small areas $\left(10 \mathrm{~cm}^{2}\right.$ ) of lens tissue sample were taken throughout the day (the collection method was a combination of allowing migration into the lens tissue over approximately $1 \mathrm{~h}$, and brushing the tissue lightly across the surface of the biofilm). It should be noted that the lens tissue method selects mainly motile species and therefore may influence the MPB assemblage of the suspensions. These samples were shaken in filtered seawater ([TIC] $3.1 \pm$ $0.1 \mathrm{mmol} \mathrm{C} \mathrm{l}^{-1}, \mathrm{n}=48$, mean $\pm \mathrm{SD}$ ), mixed and refiltered through $1 \mathrm{~mm}$ gauze, to produce a dilute algal suspension for radiocarbon and pulse amplitude modulated (PAM) fluorescence measurements.

PAM fluorescence methodology. In situ photosynthetic activity was measured at random positions (selected using a random number table) using a portable PAM fluorometer (MiniPAM, H. Walz) and a dark adaptation chamber which kept the fiberoptic probe of the fluorometer at a fixed distance of $4 \mathrm{~mm}$ from the sediment surface (Jesus et al. 2006b). After 1 min of dark adaptation, a $P$-E curve was obtained with 8 sequential irradiance steps (96 to $600 \mu \mathrm{mol}$ quanta $\mathrm{m}^{-2} \mathrm{~s}^{-1}$ ) each of 1 min duration, using the internal halogen light source of the fluorometer. Between 5 and $10 P$-E curves were collected per sampling event.

Measurements of photosynthetic activity of the algal suspension were carried out using a WaterPAM $(\mathrm{H}$. 
Walz). A $2 \mathrm{ml}$ sample of the algal suspension was placed in the quartz cuvette of the WaterPAM, the stirring lid was replaced, and a $P-E$ curve was initiated using 8 sequential irradiance steps (52 to $835 \mu \mathrm{mol}$ quanta $\mathrm{m}^{-2} \mathrm{~s}^{-1}, 15 \pm 1^{\circ} \mathrm{C}$ ) each of 1 min duration, using the red LED light source of the fluorometer. Between 3 and $6 P$-E curves were collected per sampling event.

The effective quantum efficiency of non-cyclic electron transport (i.e. $\Delta F / F_{\mathrm{m}}{ }^{\prime}$ ) during illumination was calculated as:

$$
\Delta F / F_{\mathrm{m}}{ }^{\prime}=\left(F_{\mathrm{m}}{ }^{\prime}-F\right) / F_{\mathrm{m}}{ }^{\prime}
$$

where $F$ is the steady-state fluorescence and $F_{\mathrm{m}}$ ' the maximum fluorescence after a saturating pulse $(0.6 \mathrm{~s}$ pulse duration, $6000 \mu \mathrm{mol} \mathrm{m} \mathrm{m}^{-2} \mathrm{~s}^{-1}$ ) when measured in the light. Fluorescence yields $\left(F\right.$ and $\left.F_{\mathrm{m}}{ }^{\prime}\right)$ measured in situ and on suspensions were corrected for background fluorescence using the measured background fluorescence of the sediment before inoculation and filtered $(0.2 \mu \mathrm{m}$ mesh size) suspensions, respectively. This correction was particularly important at the beginning of the growth phase when the [chl a] of both the sediment and suspensions was very low.

Using $\Delta F / F_{\mathrm{m}}{ }^{\prime}$, the linear ETR ( $\mu \mathrm{mol} \mathrm{e}^{-}[\mathrm{mg} \mathrm{chl} \mathrm{a}]^{-1} \mathrm{~s}^{-1}$ ) can be calculated per mg chl a (Hofstraat et al. 1994, Kromkamp \& Forster 2003):

$$
\mathrm{ETR}=n_{\mathrm{PSII}} \times a^{*}{ }_{\mathrm{PSII}} \times E \times \Delta F / F_{\mathrm{m}}{ }^{\prime}
$$

where $n_{\text {PSII }}$ is the number of functional PSII centres per mg chl $a, a^{*}$ PSII is the optical cross-section of PSII $\left(\mathrm{m}^{2}\right.$ photon $^{-1}$ ) and $E$ is the incident irradiance ( $\mu$ mol quanta $\mathrm{m}^{-2} \mathrm{~s}^{-1}$ ).

However, $a^{*}$ PSII and $n_{\text {PSII }}$ are difficult to measure; thus, an approximation of the proportion of incident irradiance absorbed by PSII is usually required. For this we used the spectrally averaged (400 to $700 \mathrm{~nm}$ ) chlorophyll-specific absorption cross-section $\left(a^{*}\right)$ of the MPB suspensions measured via the quantitative filter technique (QFT) (Roesler 1998). A $\beta$-factor of 2 was used to correct for path length amplification and a mean filter absorption spectrum was used to correct for variations in the optical properties of individual filters. A relatively good approximation of $a^{*}{ }_{\text {PSII }}$ and $n_{\text {PSII }}$ (Suggett et al. 2004) can be obtained by assuming that the ratio of PSI:PSII cross-sections $(\rho)$ is 0.5 (Gilbert et al. 2000). For comparison, considering the difficulty of measuring MPB absorption spectra in situ without sediment contamination, we also calculated the specific absorption cross-section in the absence of package effects $\left(a^{*}{ }_{p h}\right)$ from HPLC-derived pigment concentrations (which can easily be extracted from large numbers of sediment samples). Hypsochromic shifts and weight-specific spectral absorption coefficients (in HPLC solvent) were made according to Bidigare et al. (1990). A relative measure of the extent of pigment packaging within the suspensions was derived by comparing the measured and reconstructed specific absorption coefficients at the $680 \mathrm{~nm}$ chl a peak $\left(a^{*}{ }_{680}\right)$.

To correct for the different spectral properties of each of the light sources used to derive photosynthetic parameters, the specific spectral irradiance absorbed by the MPB assemblage $\left(\mathrm{AQ}, \mu \mathrm{mol}\right.$ quanta $[\mathrm{mg} \mathrm{chl} \mathrm{a}]^{-1}$ $\mathrm{s}^{-1}$ ) was calculated as the product of the measured specific absorption spectrum $a^{*}(\lambda)$ and the spectrum of the light source $Q(\lambda)$ for each light treatment (Kroon et al. 1993), measured with a MACAM SR9910 spectroradiometer. Thus, ETR was calculated as:

$$
\mathrm{ETR}=\mathrm{AQ} \times \rho \times \Delta F / F_{\mathrm{m}}{ }^{\prime}
$$

Rates of carbon incorporation $\left(P_{\mathrm{g}}^{\mathrm{B}}, \mu \mathrm{mol} \mathrm{C}\right.$ [mg $\mathrm{chl} \mathrm{a}]^{-1} \mathrm{~h}^{-1}$ ) were calculated from the product of ETR ( $\mu \mathrm{mol} \mathrm{e}^{-}$[mg chl a $]^{-1} \mathrm{~s}^{-1}$ ) and $\Phi_{\mathrm{e}}\left(\mathrm{mol} \mathrm{C}[\mathrm{mol} \mathrm{e}]^{-1}\right.$ where:

$$
P_{\mathrm{g}}^{\mathrm{B}}=\mathrm{ETR} \times \Phi_{\mathrm{e}}
$$

A constant $\Phi_{\mathrm{e}}$ of $0.199 \mathrm{~mol} \mathrm{C}\left(\mathrm{mol} \mathrm{e}^{-}\right)^{-1}$ (i.e. 5 electrons required and produced by PSII per C molecule; calculated by Morris \& Kromkamp 2003) was used throughout the experimental period $\left(\Phi_{\mathrm{e}}\right.$ was decided $a$ priori).

Radiocarbon assay. The algal suspension was also used to measure 3 replicate $P$ - $E$ curves per sampling event in a photosynthetron (Lewis \& Smith 1983). Algal suspension $(2 \mathrm{ml}$ ) was dispensed into $20 \mathrm{ml}$ glass vials, into which $400 \mu \mathrm{l}$ of $\mathrm{Na}^{14} \mathrm{HCO}_{3}$ (final activity of $3.7 \times$ $10^{4} \mathrm{~Bq}$ sample ${ }^{-1}$ ) were added. Vials were kept in the dark for $5 \mathrm{~min}$, prior to exposure for $30 \mathrm{~min}$ to 9 irradiances ranging from 0 to $1640 \mu \mathrm{mol}$ photon $\mathrm{m}^{-2} \mathrm{~s}^{-1}$ at the same experimental temperature as the fluorescence measurements $\left(15 \pm 1^{\circ} \mathrm{C}\right)$. The incubation was terminated by adding glutaraldehyde (3\% final concentration) and non-incorporated $\mathrm{C}$ was removed by adding $100 \mu \mathrm{l}$ of concentrated $\mathrm{HCl}$. Packard scintillation cocktail was added to each sample, and ${ }^{14} \mathrm{C}$ incorporation was measured with a Packard Tri-Carb 2300 TR scintillation counter, including quench correction. The dark incorporation rates were subtracted from the incorporation rates in the light. DIC in the medium was determined by potentiometric titration of carbonate alkalinity (Parsons et al. 1984).

The relationship between $P^{\mathrm{B}}$ and $\mathrm{AQ}$ was fitted to the model proposed by Webb et al. (1974). From the fit, the maximum photosynthetic capacity $\left(P^{\mathrm{B}}{ }_{\max }, \mu \mathrm{mol} \mathrm{C}\right.$ [mg chl a $]^{-1} \mathrm{~h}^{-1}$ ) and maximum quantum yield of photosynthesis $\left.\left(\Phi_{\mathrm{m}} \text {, mol C [mol quanta }\right]^{-1}\right)$ were derived (Sakshaug et al. 1997). Curve-fitting was done using simultaneous least-squares regression. A decrease in $P_{\mathrm{g}}^{\mathrm{B}}$ at high irradiance was not observed in the $P-E$ curves.

Statistical analyses. Bartlett's test was used to check for homogeneity of variances and the data were exam- 
ined graphically for deviations from the normal distribution. $\Delta F / F_{\mathrm{m}}{ }^{\prime}$ was arcsine transformed before statistical analysis. Statistical assumptions (homogeneity of variance and normal distribution) were valid; thus, parametric statistical tests were used. On each day (Days 7, 12, and 15), nested ANOVA was used to test for significant variation between the photosynthetic parameters estimated by each method (nested within time of day). Posthoc Tukey Unequal N HSD test was used to determine significant differences between group means within the ANOVA setting. The difference/effect was considered significant at the $\mathrm{p}<0.05$ level. Curve fitting was carried out using minimum least squares criteria in SigmaPlot 8.0 (SPSS). Confidence intervals were chosen as the expression of error for reported means within figures. All confidence intervals (CI) are given at the $95 \%$ level. Statistical analyses were performed in Statistica 6 (StatSoft).
Table 1. Biomass-specific growth, maximum quantum efficiency of Photosystem II (PSII) $\left(F_{\mathrm{v}} / F_{\mathrm{m}}\right)$ and absorption properties $\left(\mathrm{m}^{2}[\mathrm{mg} \mathrm{chl} \mathrm{a}]^{-1}\right.$ ) of the microphytobenthos (MPB) assemblage on each day of the growth period when photosynthetic parameters were compared (Days 7,12 and 15). $a^{*}$ and $a^{*}{ }_{676}$ : spectrally averaged and $676 \mathrm{~nm}$ specific chl $a$ normalised absorption cross-sections of MPB suspensions measured using the quantitative filter technique. $a^{*}{ }_{\mathrm{ph}}$ and $a^{*}{ }_{\mathrm{ph} 676}$ : spectrally averaged and $676 \mathrm{~nm}$ specific chl a normalised absorption cross-sections calculated from HPLC-derived pigment concentrations in the absence of packageeffects. See 'Materials and methods' for details. Confidence intervals are at the $95 \%$ level

\begin{tabular}{|lccc|}
\hline Property & Day 7 & Day 12 & Day 15 \\
\hline $\begin{array}{l}\text { Sediment }[\mathrm{chl} \mathrm{a}] \\
\left(\mathrm{mg} \mathrm{chl} \mathrm{m}^{-2}\right)\end{array}$ & $96 \pm 25$ & $236 \pm 8$ & $253 \pm 5$ \\
$\begin{array}{l}\text { Suspension }[\mathrm{chl} a] \\
\left(\mathrm{mg} \mathrm{chl} \mathrm{a} \mathrm{m}^{-3}\right)\end{array}$ & $17 \pm 4$ & $154 \pm 36$ & $139 \pm 38$ \\
$\begin{array}{l}\text { Biomass-specific } \\
\text { production }\left(\mathrm{d}^{-1}\right)\end{array}$ & 0.46 & 0.053 & 0.018 \\
$F_{\mathrm{v}} / F_{\mathrm{m}}$ & $0.65 \pm 0.05$ & $0.67 \pm 0.04$ & $0.61 \pm 0.07$ \\
$a^{*}$ & $0.0126 \pm 0.002$ & $0.0094 \pm 0.002$ & $0.0081 \pm 0.001$ \\
$a^{*}$ ph & $0.0163 \pm 0.0004$ & $0.0161 \pm 0.0002$ & $0.164 \pm 0.0005$ \\
$a^{*}{ }_{676}$ & $0.0178 \pm 0.003$ & $0.0152 \pm 0.003$ & $0.0127 \pm 0.002$ \\
$a^{*}$ ph676 & 0.0192 & 0.0193 & 0.0193 \\
\hline
\end{tabular}

\section{RESULTS}

Biofilm formation followed a sigmoid logistic-type curve, reaching a maximum biomass of $272 \mathrm{mg} \mathrm{chl} \mathrm{a} \mathrm{m}^{-2}$ after $19 \mathrm{~d}$ (Fig. 1). Daily biomass-specific production was estimated from the modelled changes in mean daily [chl a]. Table 1 summarises the [chl a], specific growth rate, maximum quantum efficiency of PSII charge separation $\left(F_{\mathrm{v}} / F_{\mathrm{m}}\right)$ and specific absorption properties of the assem-

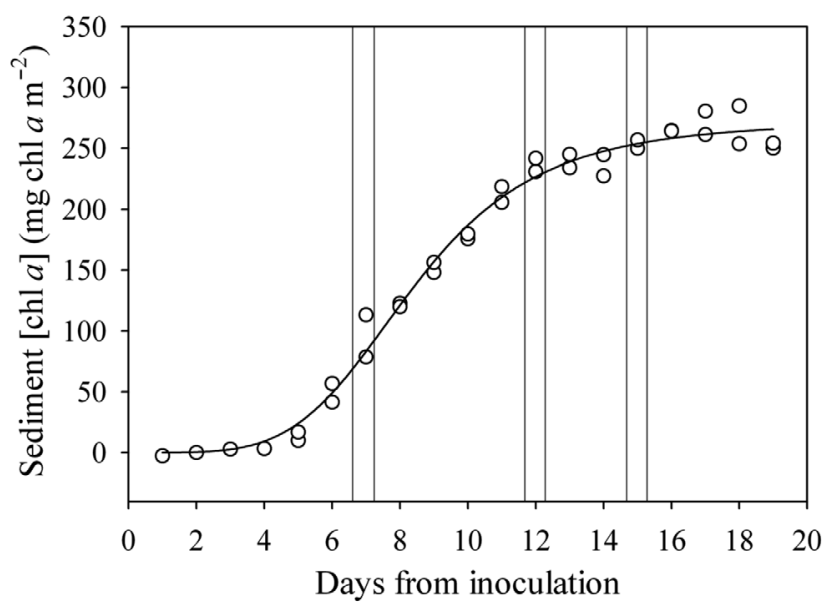

Fig. 1. Sediment chlorophyll a concentrations estimated using field spectrometry plotted as a function of cultivation time (d). A logistic curve (see 'Materials and methods' for details) was fitted to the data (solid line). Photosynthetic parameters were compared on Days 7,12 and 15 blage on each of the days when photosynthetic parameters were compared. $F_{\mathrm{v}} / F_{\mathrm{m}}$ declined slightly from around 0.66 to 0.61 on Day 15, indicating a reduction in the MPB communities' maximum quantum efficiency of photosynthesis $\left(\Phi_{\mathrm{m}}\right)$, which was probably related to reaching the stationary stage of growth (i.e. limitation of growth rates by one or more factors). Still, the relatively high $F_{\mathrm{v}} / F_{\mathrm{m}}$ value of 0.61 observed on Day 15 suggests that the biofilm was in good 'health'. The specific absorption cross-section $\left(\mathrm{a}^{*}\right)$ of the MPB suspensions measured using the QFT declined from a value of $0.0126 \pm 0.002$ to $0.0081 \pm 0.001 \mathrm{~m}^{2}(\mathrm{mg} \mathrm{chl} \mathrm{a})^{-1}($ mean $\pm \mathrm{CI})$ on Days 7 and 15 respectively, whilst $a^{*}{ }_{\mathrm{ph}}$ reconstructed from the pigment concentrations appeared constant between days, suggesting an increasing effect of pigment packaging as growth of the biofilm proceeded (Fig. 2). Comparison of $a^{*}{ }_{680}$ revealed the same general pattern, indicating a reduction (ca. $30 \%$ ) of in vivo chl a-specific absorption between Days 7 and 15.

Maximum photosynthetic capacity per unit chlorophyll $\left(P_{\text {max }}^{\mathrm{B}}\right)$ of the MPB assemblage measured using the different methods ranged from a maximum value of 859 to a minimum of $252 \mu \mathrm{mol} \mathrm{C} \mathrm{(mg} \mathrm{chl} \mathrm{a)})^{-1} \mathrm{~h}^{-1}$ on Days 7 and 15, respectively (Fig. 3). Significant differences between $P^{\mathrm{B}}{ }_{\max }$ estimates were observed on Days 12 and 15 (Table 2). On Day 12, measurements made in suspensions were significantly lower than those made in situ at the end of the emersion period; however, on Day 15, this difference was apparent from the middle of the emersion period (Fig. 3, post-hoc Tukey unequal N HSD test, $\mathrm{p}<0.05)$. 

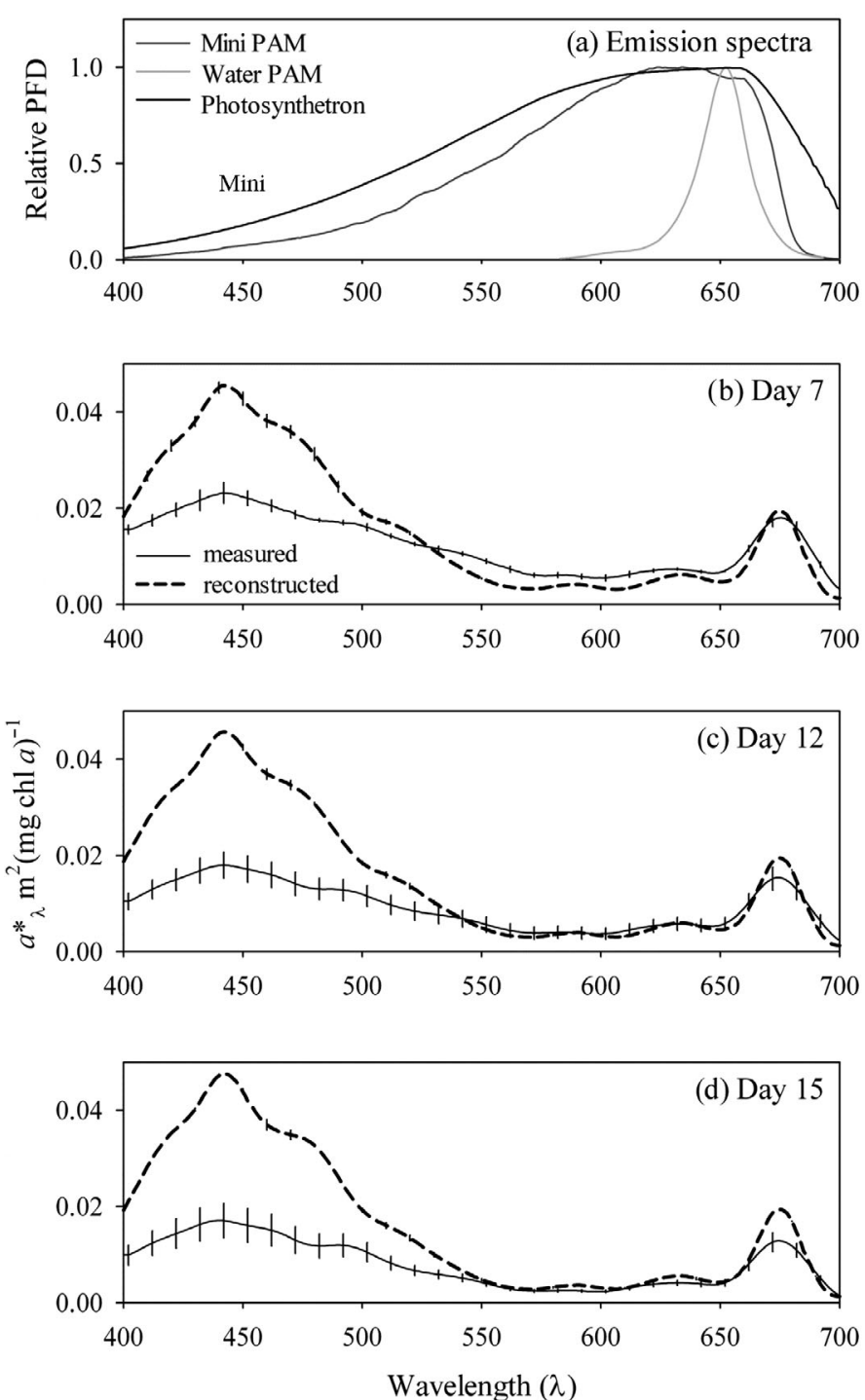

Fig. 2. (a) Relative emission spectra (PFD: photon flux density) of the light sources used during photosynthetic incubations. (b-d) Measured and reconstructed (using HPLC-derived pigments) chlorophyll-specific absorption cross-sections of the microphytobenthos (MPB) suspensions $\left(a^{*} \lambda\right)$ on (b) Day 7 , (c) Day 12, and (d) Day 15 of cultivation. Vertical lines represent $\pm 1 \mathrm{SD}(\mathrm{n}=9)$

Examination of $\Delta F / F_{\mathrm{m}}{ }^{\prime}$ values from light steps in the irradiance-saturated region of the $P$-E curves (where the $A Q$ values from each method were very similar), measured in situ and on suspensions, revealed significant differences between methods on Days 12 and 15 (Table 3, Fig. 4). $\Delta F / F_{\mathrm{m}}{ }^{\prime}$ measured in situ appeared to be overestimated relative to the suspensions from the middle of the emersion period on both days (Fig. 4, post-hoc Tukey unequal N HSD test, p < 0.05), suggesting that this effect was responsible for the differences in $P^{\mathrm{B}}{ }_{\text {max }}$ estimates measured on sediment and in supension.
$\Phi_{\mathrm{m}}$ (i.e. the initial slope of the $P$ - $E$ curve), measured using the different methods, ranged from a maximum value of 0.072 to a minimum of $0.055 \mathrm{~mol} \mathrm{C} \mathrm{(mol}$ quanta) $)^{-1}$ on Days 7 and 15, respectively (Fig. 5). Significant differences between $\Phi_{\mathrm{m}}$ values derived by the 3 methods were only observed on Day 15 (Fig. 5, Table 4). This difference was related to an overestima-
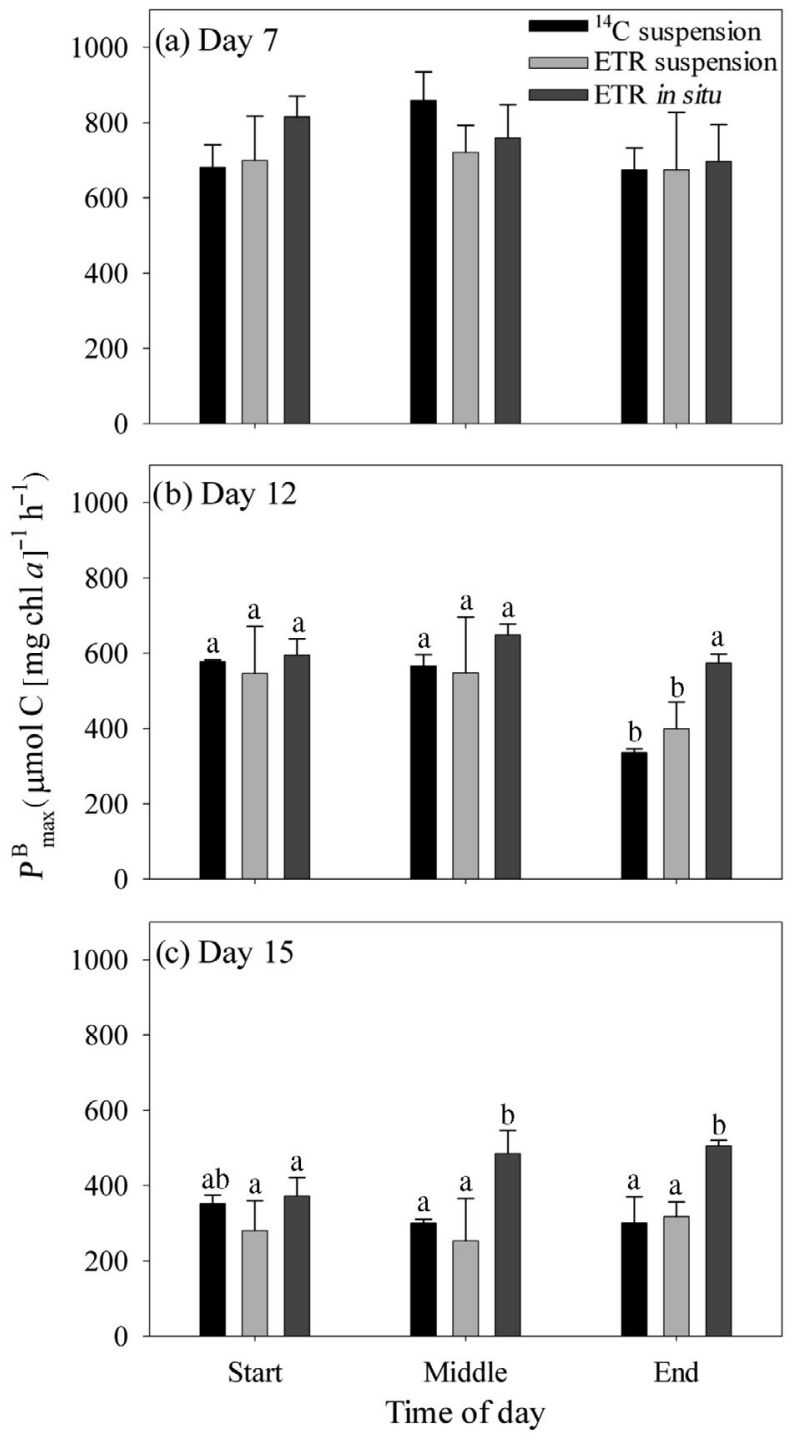

Fig. 3. Biomass-specific maximum rates of carbon assimilation $\left(P_{\max }^{\mathrm{B}}\right)$ at the start $(1 \mathrm{~h}$ emersion), middle $(4 \mathrm{~h}$ emersion $)$, and end $(7 \mathrm{~h}$ emersion) of the daytime low tide on (a) Day 7 , (b) Day 12, and (c) Day 15 of cultivation. Rates were measured as follows: (1) rate of ${ }^{14} \mathrm{C}$-bicarbonate uptake in an algal suspension $\left({ }^{14} \mathrm{C}\right.$ suspension); (2) electron transport rates (ETR) in an algal suspension converted to carbon assimilation (ETR suspension); and (3) ETR measured on undisturbed sediment converted to carbon assimilation (ETR in situ). For details of ETR conversions see 'Materials and methods' (mean \pm CI, $\mathrm{n}=$ 3 to 10). Significant differences between photosynthetic parameters are indicated by lowercase letters (post hoc Tukey unequal N HSD test, $\mathrm{p}<0.05$ ) 
tion of $\Phi_{\mathrm{m}}$ measured in situ compared to measurements made with ${ }^{14} \mathrm{C}$ on suspensions at the beginning and the end of the emersion period (Fig. 5) (post-hoc Tukey unequal N HSD test, $\mathrm{p}<0.05$ ).

Table 2. Nested ANOVA comparing biomass-specific maximum rates of carbon assimilation $\left(P^{\mathrm{B}}{ }_{\max }, \mu \mathrm{mol} \mathrm{C}[\mathrm{mg} \mathrm{chl} \mathrm{a}]^{-1}\right.$ $\mathrm{h}^{-1}$ ) measured using ${ }^{14} \mathrm{C}$ uptake in suspension, ETR in suspension and ETR on undisturbed sediment (Method). Comparisons were carried out on Days 7, 12, and 15 from cultivation at the start ( $1 \mathrm{~h}$ emersion), middle ( $4 \mathrm{~h}$ emersion), and end ( $7 \mathrm{~h}$ emersion) of the daytime low tide (Time). Analyses were conducted on each day separately with Method nested within Time

\begin{tabular}{|llrrr|}
\hline & & df & $F$ & $\mathrm{p}$ \\
\hline Day 7 & Method (Time) & 6 & 2.11 & 0.075 \\
& Time & 2 & 4.01 & 0.027 \\
& Error & 37 & & \\
Day 12 & Method (Time) & 6 & 9.74 & $<0.001$ \\
& Time & 2 & 25.58 & $<0.001$ \\
& Error & 45 & & \\
Day 15 & Method (Time) & 6 & 19.41 & $<0.001$ \\
& Time & 2 & 1.56 & 0.219 \\
& Error & 50 & & \\
& & & & \\
& & & & \\
& & & & \\
& & & & \\
& & &
\end{tabular}

Table 3. Nested ANOVA comparing effective quantum efficiency $\left(\Delta F / F_{\mathrm{m}}\right)$ at the highest light steps measured on suspensions and undisturbed sediment. Values were arcsine transformed before analysis. Other details as in Table 2

\begin{tabular}{|llrrr|}
\hline & & df & $F$ & \multicolumn{1}{c|}{ p } \\
\hline Day 7 & Method (Time) & 3 & 2.31 & 0.081 \\
& Time & 2 & 2.06 & 0.133 \\
& Error & 97 & & \\
Day 12 & Method (Time) & 3 & 20.48 & $<0.001$ \\
& Time & 2 & 3.94 & 0.024 \\
& Error & 76 & & \\
Day 15 & Method (Time) & 3 & 47.92 & $<0.001$ \\
& Time & 2 & 2.73 & 0.075 \\
& Error & 47 & & \\
\hline
\end{tabular}

Table 4. Nested ANOVA comparing maximum quantum yield $\left(\Phi_{\mathrm{m}}\right.$ i mol C $\left[\mathrm{mol}\right.$ quanta $\left.{ }^{-1}\right)$ measured using the 3 methods. Other details as in Table 2

\begin{tabular}{|llrrr|}
\hline & & df & $F$ & $p$ \\
\hline Day 7 & Method (Time) & 6 & 2.15 & 0.070 \\
& Time & 2 & 0.62 & 0.546 \\
& Error & 37 & & \\
Day 12 & Method (Time) & 6 & 2.24 & 0.057 \\
& Time & 2 & 6.53 & 0.003 \\
& Error & 43 & & \\
Day 15 & Method (Time) & 6 & 13.57 & $<0.001$ \\
& Time & 2 & 0.67 & 0.519 \\
& Error & 47 & & \\
\hline
\end{tabular}
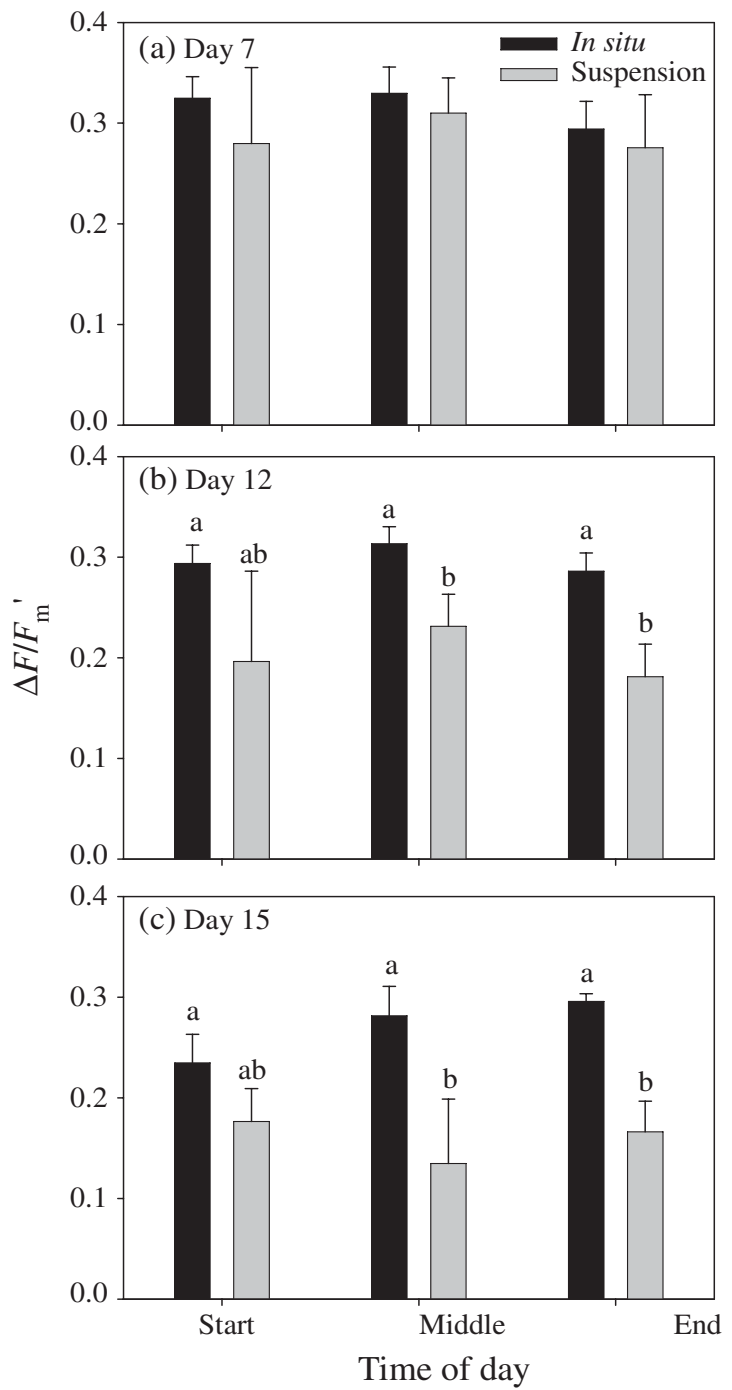

Fig. 4. Effective quantum efficiency $\left(\Delta F / F_{\mathrm{m}}{ }^{\prime}\right)$ from light steps in the irradiance-saturated region of the photosynthesisirradiance $(P-E)$ curves (where the $\mathrm{AQ}$ values from each method were similar) at the start (1 $\mathrm{h}$ emersion), middle $(4 \mathrm{~h}$ emersion), and end ( $7 \mathrm{~h}$ emersion) of the daytime low tide on (a) Day 7, (b) Day 12, and (c) Day 15 of cultivation. Other details as in Fig. 3

\section{DISCUSSION}

Sediment $[\mathrm{chl}$ a], growth rates, and photosynthetic parameters observed during the growth of the experimental MPB assemblage were representative of the ranges of values reported in the literature for natural MPB assemblages (Gould \& Gallagher 1990, Underwood \& Kromkamp 1999, Wolfstein et al. 2000).

Specific absorption coefficients were also similar to those previously reported for benthic diatoms (Morris \& Kromkamp 2003, Mercado et al. 2004). Relatively few previous studies report on the extent of pigment packaging in MPB assemblages; however, the value of 

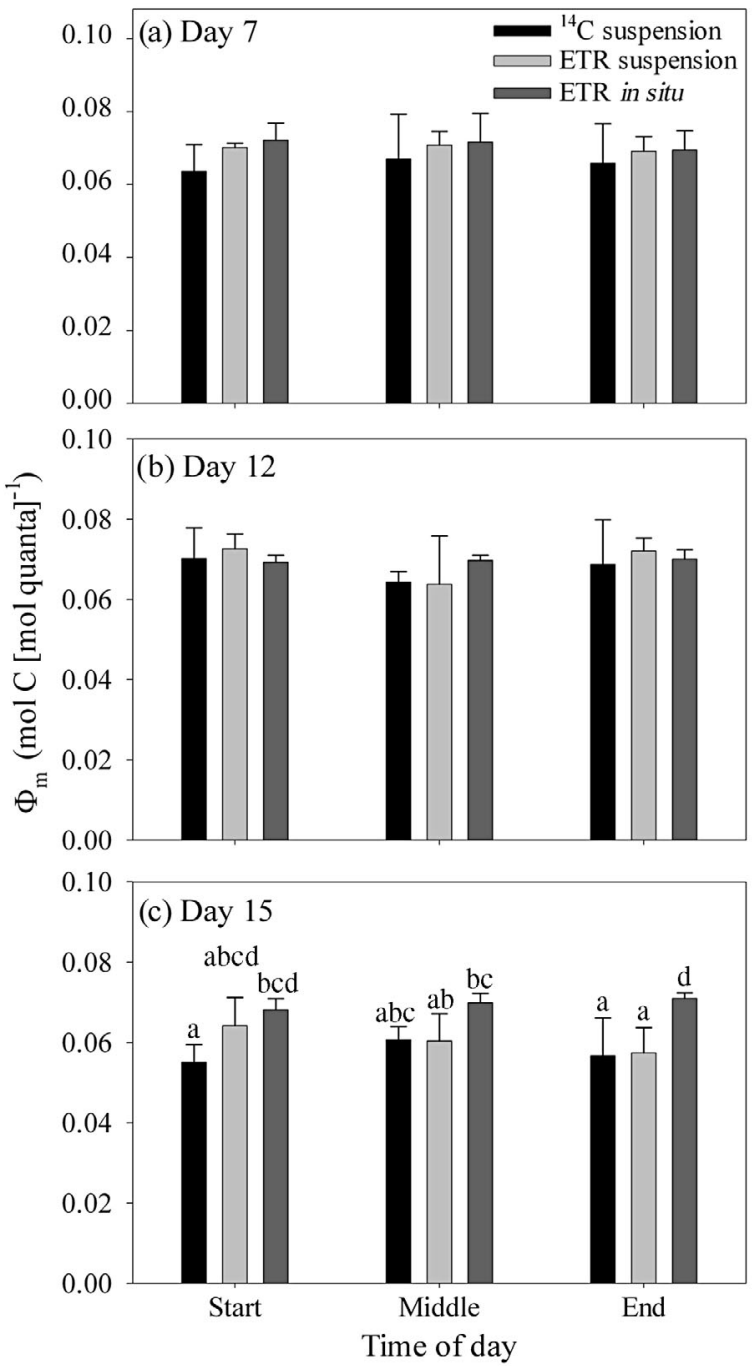

Fig. 5. Maximum quantum yield $\left(\Phi_{\mathrm{m}}\right)$ at the start $(1 \mathrm{~h}$ emersion), middle ( $4 \mathrm{~h}$ emersion), and end ( $7 \mathrm{~h}$ emersion) of the daytime low tide on (a) Day 7, (b) Day 12, and (c) Day 15 of cultivation. Other details as in Fig. 3

about $30 \%$ estimated in this study corresponds well with values reported for phytoplankton (Geider \& Osborne 1987, Berner et al. 1989) and subtidal Nitzschia and Navicula sp. (Mercado et al. 2004). HPLCderived pigment data suggest that during the entire experiment the MPB assemblage consisted only of diatoms, but in the absence of species data there is a possibility that a succession within the diatoms species occurred, and that this might have influenced the specific absorption cross-sections of the community.

It is important to note that rates of carbon fixation were calculated from PAM fluorescence measurements using measured absorption coefficients, and conversion factors determined a priori, and not via a post-hoc empirical comparison. Thus, our results appear to confirm that the photosynthetic parameters derived via PAM fluorescence measurements of MPB assemblages in suspensions were reliable when compared to standard methods, i.e. they were not significantly different from those determined using the radiocarbon method (Figs. 3 \& 5). Thus, the photosynthetic parameters matched, even when, due to the technical limitations of the different methods, different lengths of light step incubations (i.e. $1 \mathrm{~min}$ for the PAM fluorescence measurements and $30 \mathrm{~min}$ for ${ }^{14} \mathrm{C}$ uptake) were used during the comparison. This suggests that $1 \mathrm{~min}$ was long enough for $\Delta F / F_{\mathrm{m}}$ ' values to reach a 'steadystate' and that photoinhibitory effects did not occur during the longer photosynthetron incubations. The derived photosynthetic parameters are also in agreement with theoretical predictions of the minimum quantum requirement of carbon fixation $\left(\mathrm{QR}, 1 / \Phi_{\mathrm{m}}\right)$ (Ley \& Mauzerall 1982). Values of the QR calculated in this study ranged from a maximum of 18.2 quanta $(C)^{-1}$ to a minimum of 13.8 quanta $(\mathrm{C})^{-1}$, which is very close to the theoretical minimum of between 10.1 and 14.1 (depending on the photosynthetic quotient used) derived by Ley \& Mauzerall (1982). This suggests that over the range of growth conditions examined, the use of variable fluorescence as an alternative method for estimating the photosynthetic parameters of MPB algal suspensions seems to offer considerable promise, a conclusion previously reached by a number of other authors (Flameling \& Kromkamp 1998, Gilbert et al. 2000, Morris \& Kromkamp 2003).

However, significant differences were observed between photosynthetic parameters measured in situ and on suspensions (Figs. 3 \& 5). These differences were characterised by a tendency of ETR in situ to overestimate $\Delta F / F_{\mathrm{m}}{ }^{\prime}$ at the highest light steps (Fig. 4), which became more pronounced during the later stages of biofilm development and towards the end of emersion periods. The interaction of these effects led to $40-60 \%$ overestimation of $P^{\mathrm{B}}{ }_{\max }$ on Days 12 and 15, but had a much smaller influence on $\Phi_{\mathrm{m}}$. This seems to indicate the presence of 'deep-layer fluorescence' (DLF), i.e. fluorescence originating from algae below the surface (Oxborough et al. 2000, Perkins et al. 2002). The magnitude of $\Delta F / F_{\mathrm{m}}{ }^{\prime}$ overestimation in situ also agrees very well with predictions derived via modelling the contribution of fluorescence originating at depths below the sediment surface (Forster \& Kromkamp 2004, Serôdio 2004). This effect has been reported for measurements made on optically complex structures such as plant leaves, macroalgal thalli or benthic biofilms. In the presence of light, subsurface algae (or chloroplasts) are exposed to lower irradiances than algae at the sediment surface, and will have a correspondingly higher $\Delta F / F_{\mathrm{m}}{ }^{\prime}$. A fraction of the fluorescence from this layer will be detectable at the surface, causing an apparent overestimation of $\Delta F / F_{\mathrm{m}}{ }^{\prime}$ of 
the algae on the sediment surface. The effect is more pronounced at irradiances exceeding the light saturation parameter $\left(E_{\mathrm{k}}\right)$, and with higher [chl a] (Forster \& Kromkamp 2004, Serôdio 2004) and, thus, seems to be a likely explanation for the observed divergence between $\Delta F / F_{\mathrm{m}}{ }^{\prime}$ values.

Intriguingly, time (relative to the onset of emersion) was also important in determining the extent of this effect. Changes in the vertical distribution of cells, in particular a subsurface peak in cell numbers (as might be induced when cells migrate away from the sediment surface), can cause a strong enhancement of DLF effects (Forster \& Kromkamp 2004, Serôdio 2004, Serôdio et al. 2007); thus, it seems probable that the interaction of DLF effects with time is most likely related to vertical migration of the assemblage.

Migration is an important aspect of MPB ecology and has been proposed to have a number of functions (Barranguet et al. 1998, Kingston 2002, Tolhurst et al. 2003, Consalvey et al. 2004). In terms of the influence on variable fluorescence measurements, 3 working definitions can be made: (1) bulk migration of the whole assemblage over the emersion period, (2) migration in response to irradiance (phototaxis), and (3) single species migrations. Bulk migration can usually be easily observed using field spectrometry (Paterson et al. 1998), and in our study (judging by daily changes in NDVI) did not appear to take place; however, using our experimental setup, we are unable to be certain whether phototactic migrations and single species migrations occurred. Jesus et al. (2006a) demonstrated that phototaxis-like migrations of MPB can lead to overestimations of in situ $\Delta F / F_{\mathrm{m}}{ }^{\prime}$ and that this effect can be dependent on the time relative to the onset of emersion. Underwood et al. (2005) also demonstrated that species-specific migrations throughout the emersion period (which are likely to have a minimum influence on total sediment absorption properties and thus be difficult to observe with field spectrometry measurements) can also result in overestimation of in situ $\Delta F / F_{\mathrm{m}}{ }^{\prime}$.

Thus, it seems likely that a combination of DLF, phototaxis, and/or species migrations were responsible for the overestimation of $P^{\mathrm{B}}$ max measured on undisturbed sediments when compared to suspensions of MPB in well-developed biofilms. These effects were influenced by the length of emersion and were most prominent at high biomass when the assemblage had very low growth rates. Thus, we found that the quantification of in situ photosynthetic parameters on undisturbed sediments using variable fluorescence was not reliable when examined over a representative range of MPB growth conditions. In contrast, comparisons of variable fluorescence and radioisotope-derived photosynthetic parameters measured on optically thin sus- pensions were not significantly different, confirming that, with an appropriate estimation of the irradiance absorbed by PSII, variable fluorescence is a reliable measure of MPB photosynthetic rates under optically well-defined conditions.

These results highlight one of the major problems associated with the determination of 'absolute' ETR: estimating the amount of light absorbed by PSII is very difficult (Baker \& Oxborough 2004). In muddy sediments, further to overcoming the technical difficulties of measuring the specific absorption cross-section of the cells in situ, accurate determination of the vertical distribution of spectral irradiance and [chl a] is also required. Using this information, in situ ETR can, in principle, be corrected for DLF and accurate predictions of depth-integrated primary production can then still be made by multiplying ETR with the minimum fluorescence $\left(F_{0}\right)$ (Forster \& Kromkamp 2004, Serôdio et al. 2007). Nevertheless, the complex vertical migration behavioural strategies of MPB species implies that the light absorbed by the MPB assemblage can change at very short time scales, and for this reason it is best to avoid the first 45 to $60 \mathrm{~min}$ after the tides leave or before they return because these are the periods when the major vertical migration takes place. Field spectrometry and the use of fluorescence imaging systems may provide convenient ways of obtaining information about vertical migration and about changes in the light exposure. Thus, until a convenient method has been developed to measure the absorption coefficient and vertical distribution in situ, chlorophyll-specific photosynthetic parameters of MPB derived using variable fluorescence in situ on undisturbed sediments should be interpreted with care and should preferably be combined with measurements on optically thin slurries of MPB.

Acknowledgements. The authors thank V. Creach for assistance with measurements and identification of species, B. Sinke for help with the experimental setup, J. Sinke for pigment analyses, D. Suggett for helpful discussion, and the anonymous reviewers for their valuable comments which greatly improved this manuscript. This work was supported by grants from the EU (BIOPTIS MAS3-CT97-0158 and HIMOM EVK3-CT-2001-00051). This is NIOO-KNAW publication 4257.

\section{LITERATURE CITED}

Baker NR, Oxborough K (2004) Chlorophyll fluorescence as a probe of photosynthetic productivity. In: Papageorgiou GC, Govindjee (eds) Chlorophyll a fluorescence: a signature of photosynthesis, Vol 19. Springer, Dordrecht, p 65-82

Barranguet C, Kromkamp J (2000) Estimating primary production rates from photosynthetic electron transport in estuarine microphytobenthos. Mar Ecol Prog Ser 204: $39-52$ 
Barranguet C, Kromkamp J, Peene J (1998) Factors controlling primary production and photosynthetic characteristics of intertidal microphytobenthos. Mar Ecol Prog Ser 173:117-126

Berner T, Dubinsky Z, Wyman K, Falkowski P (1989) Photoadaption and the 'package' effect in Dunaliella tertiolecta (Chlorophyceae). J Phycol 25:70-78

Bidigare RR, Ondrusek ME, Morrow J, Kiefer DA (1990) In vivo absorption properties of algal pigments. SPIE Ocean Optics X 1302:290-302

Blanchard GF, Carioulegall V (1994) Photosynthetic characteristics of microphytobenthos on an intertidal mudflat. J Exp Mar Biol Ecol 182:1-14

Blanchard GF, Guarini JM, Orvain F, Sauriau PG (2001) Dynamic behaviour of benthic microalgal biomass in intertidal mudflats. J Exp Mar Biol Ecol 264:85-100

Cahoon LB (1999) The role of benthic microalgae in neritic ecosystems. Oceanogr Mar Biol Annu Rev 37:47-86

Consalvey M, Jesus B, Perkins RG, Brotas V, Underwood GJC, Paterson DM (2004) Monitoring migration and measuring biomass in benthic biofilms: the effects of dark/far-red adaptation and vertical migration on fluorescence measurements. Diatom Res 19:181-202

Cullen JJ, Davis RF (2003) The blank can make a big difference in oceanographic measurements. Limnol Oceanogr Bull 12:30-35

Eaton JW, Moss B (1966) The estimation of numbers and pigment content in epipelic algal populations. Limnol Oceanogr 11:584-595

Flameling IA, Kromkamp J (1998) Light dependence of quantum yields for PSII charge separation and oxygen evolution in eucaryotic algae. Limnol Oceanogr 43:284-297

Forster RM, Jesus B (2006) Field spectroscopy of estuarine intertidal habitats. Int J Remote Sens 27:3657-3669

Forster RM, Kromkamp JC (2004) Modelling the effects of chlorophyll fluorescence from subsurface layers on photosynthetic efficiency measurement in microphytobenthic algae. Mar Ecol Prog Ser 284:9-22

Geider RJ, Osborne BA (1987) Light absorption by a marine diatom: experimental observations and theoretical calculations of the package effect in a small Thalassiosira species. Mar Biol 96:299-308

Genty B, Briantais JM, Baker NR (1989) The relationship between the quantum yield of photosynthetic electrontransport and quenching of chlorophyll fluorescence. Biochim Biophys Acta 990:87-92

Gilbert M, Wilhelm C, Richter M (2000) Bio-optical modelling of oxygen evolution using in vivo fluorescence: comparison of measured and calculated photosynthesis/irradiance (P-I) curves in four representative phytoplankton species. J Plant Physiol 157:307-314

Gould DM, Gallagher ED (1990) Field measurement of specific growth-rate, biomass, and primary production of benthic diatoms of Savin Hill Cove, Boston. Limnol Oceanogr 35:1757-1770

Hartig P, Wolfstein K, Lippemeier S, Colijn F (1998) Photosynthetic activity of natural microphytobenthos populations measured by fluorescence (PAM) and ${ }^{14} \mathrm{C}$-tracer methods: a comparison. Mar Ecol Prog Ser 166:53-62

Hofstraat JW, Peeters JCH, Snel JFH, Geel C (1994) Simple determination of photosynthetic efficiency and photoinhibition of Dunaliella tertiolecta by saturating pulse fluorescence measurements. Mar Ecol Prog Ser 103:187-196

Jesus B, Perkins RG, Mendes CR, Brotas V, Paterson DM (2006a) Chlorophyll fluorescence as a proxy for microphytobenthic biomass: alternatives to the current methodology. Mar Biol 150:17-28
Jesus B, Perkins RG, Consalvey M, Brotas V, Paterson DM (2006b) Effects of vertical migrations by benthic microalgae on fluorescence measurements of photophysiology. Mar Ecol Prog Ser 315:55-66

Jonsson B (1991) A C-14 incubation technique for measuring microphytobenthic primary productivity in intact sediment cores. Limnol Oceanogr 36:1485-1492

Kingston MB (2002) Effect of subsurface nutrient supplies on the vertical migration of Euglena proxima (Euglenophyta). J Phycol 38:872-880

Kraay GW, Zapata M, Veldhuis MJ (1992) Separation of chlorophylls $C_{1}, C_{2}$, and $C_{3}$ of marine phytoplankton by reversed phase-C18-high-performance liquid chromatography. Proc Natl Acad Sci USA 28:708-712

Kromkamp JC, Forster RM (2003) The use of variable fluorescence measurements in aquatic ecosystems: differences between multiple and single turnover measuring protocols and suggested terminology. Eur J Phycol 38:103-112

Kromkamp J, Barranguet C, Peene J (1998) Determination of microphytobenthos PSII quantum efficiency and photosynthetic activity by means of variable chlorophyll fluorescence. Mar Ecol Prog Ser 162:45-55

Kromkamp JC, Morris EP, Forster RM, Honeywill C, Hagerthey S, Paterson DM (2006) Optical measures of intertidal sediments: relationship of surface sediment chlorophyll concentration with hyper-spectral reflectance or chlorophyll fluorescence. Estuar Coast 29:183-196

Kroon B, Prezelin BB, Schofield O (1993) Chromatic regulation of quantum yields for photosystem II charge separation, oxygen evolution, and carbon fixation in Heterocapsa-Pygmaea (Pyrrophyta). J Phycol 29:453-462

Kuhl M, Jorgensen BB (1992) Spectral light measurements in microbenthic phototrophic communities with a fiberoptic microprobe coupled to a sensitive diode-array detector. Limnol Oceanogr 37:1813-1823

Lewis MR, Smith JC (1983) A small volume, short-incubationtime method for measurement of photosynthesis as a function of incident irradiance. Mar Ecol Prog Ser 13:99-102

Ley AC, Mauzerall DC (1982) Absolute absorption crosssections for photosystem II and the minimum quantum requirement for photosynthesis in Chlorella vulgaris. Biochim Biophys Acta 680:95-106

MacIntyre HL, Cullen JJ (1995) Fine-scale vertical resolution of chlorophyll and photosynthetic parameters in shallowwater benthos. Mar Ecol Prog Ser 122:227-237

MacIntyre HL, Geider RJ, Miller DC (1996) Microphytobenthos - the ecological role of the secret garden of unvegetated, shallow-water marine habitats. 1. Distribution, abundance and primary production. Estuaries 19:186-201

> Masojídek J, Grobbelaar JU, Pechar L, Koblizek M (2001) Photosystem II electron transport rates and oxygen production in natural waterblooms of freshwater cyanobacteria during a diel cycle. J Plankton Res 23:57-66

Mercado JM, Sanchez-Saavedra MP, Correa-Reyes G, Lubian L, Montero O, Figueroa FL (2004) Blue light effect on growth, light absorption characteristics and photosynthesis of five benthic diatom strains. Aquat Bot 78: 265-277

Middelburg JJ, Barranguet C, Boschker HTS, Herman PMJ, Moens T, Heip CHR (2000) The fate of intertidal microphytobenthos carbon: an in situ C-labeling study. Limnol Oceanogr 45:1224-1234

- Morris EP, Kromkamp JC (2003) The influence of temperature on the relationship between oxygen- and fluorescencebased estimates of photosynthetic parameters in a marine benthic diatom (Cylindrotheca closterium). Eur J Phycol 38:133-142 
Oxborough K, Hanlon ARM, Underwood GJC, Baker NR (2000) In vivo estimation of the photosystem II photochemical efficiency of individual microphytobenthic cells using high-resolution imaging of chlorophyll a fluorescence. Limnol Oceanogr 45:1420-1425

Parsons TR, Maita Y, Lalli CM (1984) A manual of chemical and biological methods for seawater analysis. Pergamon Press, Oxford

Paterson DM, Wiltshire $\mathrm{KH}$, Miles A, Blackburn J and others (1998) Microbiological mediation of spectral reflectance from intertidal cohesive sediments. Limnol Oceanogr 43: 1207-1221

Perkins RG, Underwood GJC, Brotas V, Snow GC, Jesus B, Ribeiro L (2001) Responses of microphytobenthos to light: primary production and carbohydrate allocation over an emersion period. Mar Ecol Prog Ser 223:101-112

Perkins RG, Oxborough K, Hanlon ARM, Underwood GJC, Baker NR (2002) Can chlorophyll fluorescence be used to estimate the rate of photosynthetic electron transport within microphytobenthic biofilms? Mar Ecol Prog Ser 228:47-56

Roesler CS (1998) Theoretical and experimental approaches to improve the accuracy of particulate absorption coefficients derived from the quantitative filter technique. Limnol Oceanogr 43:1649-1660

Sakshaug E, Bricaud A, Dandonneau Y, Falkowski PG and others (1997) Parameters of photosynthesis: definitions, theory and interpretation of results. J Plankton Res 19:1637-1670

Serôdio J (2003) A chlorophyll fluorescence index to estimate short-term rates of photosynthesis by intertidal microphytobenthos. J Phycol 39:33-46

Serôdio J (2004) Analysis of variable chlorophyll fluorescence in microphytobenthos assemblages: implications of the use of depth-integrated measurements. Aquat Microb Ecol 36:137-152

Editorial responsibility: Rutger de Wit, Montpellier, France
Serôdio J, Vieira S, Barosso F (2007) Relationship of variable chlorophyll fluorescence indices to photosynthetic rates in microphytobenthos. Aquat Microb Ecol 49:71-85

Suggett DJ, MacIntyre HL, Geider RJ (2004) Evaluation of biophysical and optical determinations of light absorption by photosystem II in phytoplankton. Limnol Oceanogr Methods 2:316-332

Tolhurst TJ, Jesus B, Brotas V, Paterson DM (2003) Diatom migration and sediment armouring - an example from the Tagus Estuary, Portugal. Hydrobiologia 503:183-193

Underwood GJC, Kromkamp J (1999) Primary production by phytoplankton and microphytobenthos in estuaries. In: Nedwell DB, Raffaelli DG (eds) Advances in ecological research, Vol 29. Academic Press, London, p 93-153

Underwood GJC, Paterson DM (2003) The importance of extracellular carbohydrate production by marine epipelic diatoms. Adv Bot Res 40:183-240

Underwood GJC, Perkins RG, Consalvey MC, Hanlon ARM, Oxborough K, Baker NR, Paterson DM (2005) Patterns in microphytobenthic primary productivity: species-specific variation in migratory rhythms and photosynthetic efficiency in mixed-species biofilms. Limnol Oceanogr 50: 755-767

Vadeboncoeur Y, Lodge DM (1998) Dissolved inorganic carbon sources for epipelic algal production: sensitivity of primary production estimates to spatial and temporal distribution of C-14. Limnol Oceanogr 43:1222-1226

Webb WL, Newton M, Starr D (1974) Carbon dioxide exchange of Alnus rubra: a mathematical model. Oecologia 17:281-291

Wolfstein K, Colijn F, Doerffer R (2000) Seasonal dynamics of microphytobenthos biomass and photosynthetic characteristics in the northern German Wadden Sea, obtained by the photosynthetic light dispensation system. Estuar Coast Shelf Sci 51:651-662

Submitted: June 21, 2007; Accepted: December 21, 2007 Proofs received from author(s): March 10, 2008 